\title{
Moving prevention of functional impairment upstream: is middle age an ideal time for intervention?
}

\author{
Rebecca T. Brown ${ }^{1,2,3^{*}}$ (D) and Kenneth E. Covinsky ${ }^{4,5}$
}

\begin{abstract}
To live independently, individuals must be able to perform basic activities of daily living (ADLs), including bathing, dressing, and transferring out of a bed or chair. When older adults develop difficulty or the need for help performing ADLs, they experience decreased quality of life and an increased risk of acute care utilization, nursing home admission, and death. For these reasons, slowing or preventing the progression to functional problems is a key focus of the care of older adults. While preventive efforts currently focus mainly on older people, difficulty performing basic ADLs ("functional impairment") affects nearly 15\% of middle-aged adults, and this prevalence is increasing. People who develop functional impairment in middle age are at increased risk for adverse outcomes similar to those experienced by older adults. Developing ADL impairment in middle age also impacts work force participation and health expenditures, not just in middle age but also older age. Middle-aged adults have a high capacity for recovery from functional impairment, and many risk factors for developing functional impairment in middle and older age have their roots in mid-life. Taken together, these findings suggest that middle age may be an ideal period to intervene to prevent or delay functional impairment. To address the rising prevalence of functional impairment in middle age, we will need to work on several fronts. These include developing improved prognostic tools to identify middle-aged people at highest risk for functional impairment and developing interventions to prevent or delay impairment among middle-aged people. More broadly, we need to recognize functional impairment in middle age as a problem that is as prevalent and central to health outcomes as many chronic medical conditions.
\end{abstract}

Keywords: Middle age, Functional limitation, Physical functioning

\section{Background}

To live independently, individuals must be able to perform basic activities of daily living (ADLs), including bathing, dressing, toileting, transferring out of a bed or chair, and feeding oneself. As people age, they may develop difficulty performing these activities, or "functional impairment." Over time or with the onset of illness,

\footnotetext{
* Correspondence: rebecca.brown@pennmedicine.upenn.edu

'Division of Geriatric Medicine, Perelman School of Medicine at the University of Pennsylvania, 3615 Chestnut Street, Philadelphia, PA 19104, USA ${ }^{2}$ Geriatrics and Extended Care, Corporal Michael J. Crescenz Veterans Affairs Medical Center, Philadelphia, PA, USA

Full list of author information is available at the end of the article
}

individuals may progress from having difficulty with daily activities to needing help from another person to perform these activities, often called "disability." When older adults develop functional impairment or disability, they experience decreased quality of life and an increased risk of acute care utilization, nursing home admission, and death [1-3]. For this reason, a large body of research has focused on identifying older adults at highest risk for developing ADL problems and developing and testing interventions targeted to those at highest risk. This research has focused almost exclusively on people ages 70 or older, and has shown that targeted

(c) The Author(s). 2020 Open Access This article is licensed under a Creative Commons Attribution 4.0 International License, which permits use, sharing, adaptation, distribution and reproduction in any medium or format, as long as you give appropriate credit to the original author(s) and the source, provide a link to the Creative Commons licence, and indicate if changes were made. The images or other third party material in this article are included in the article's Creative Commons licence, unless indicated otherwise in a credit line to the material. If material is not included in the article's Creative Commons licence and your intended use is not permitted by statutory regulation or exceeds the permitted use, you will need to obtain permission directly from the copyright holder. To view a copy of this licence, visit http://creativecommons.org/licenses/by/4.0/ The Creative Commons Public Domain Dedication waiver (http://creativecommons.org/publicdomain/zero/1.0/) applies to the data made available in this article, unless otherwise stated in a credit line to the data. 
interventions can prevent ADL problems among highrisk adults in this age group [4-6].

Yet a growing body of research shows that functional impairment is also common in middle-aged people (i.e., ages 45-64), and that the prevalence of functional impairment is increasing in this age group [7-12]. From 2000 to 2008, the prevalence of difficulty performing one or more ADLs increased from 15 to $16 \%$ among people aged 55-64 [9], an increase of approximately 420,000 people, and this upward trend continued through 2016 [12]. While needing help with ADLs remains relatively rare in middle age $[7,9,11,12]$, developing difficulty with these activities represents a key step on the pathway towards needing help and strongly predicts adverse outcomes [13, 14]. Recent research shows that developing ADL difficulty in middle age is associated with outcomes similar to those seen in late life, including hospitalization, nursing home admission, and death [13]. Developing ADL impairment in middle age also impacts work force participation and health care utilization and expenditures, not just in middle age but also older age [7, 15]. Yet while research among older adults has advanced from identifying those at risk to implementing interventions to prevent functional impairment, we lack similar progress to address functional impairment among middle-aged people.

In this commentary, we will discuss why middle age may be an ideal time to intervene to prevent or delay the development of functional impairment in both middle age and older age. We will also consider what types of interventions may be most effective in this age group.

\section{Main text}

Epidemiology and outcomes of functional impairment in middle age

Functional impairment is becoming more common in middle age

A growing body of research shows that over the past two decades, health has worsened among middle-aged people in the United States. This includes increases not only in the prevalence of functional impairment but also in the prevalence of chronic conditions such as diabetes, obesity, and arthritis [16] which are important causes of functional impairment in the United States [7, 17]. The reasons for worsening health and function in middle age are complex and an area of active study. Changing health behaviors play an important role in the increased prevalence of chronic conditions, including increases in caloric intake, changes in dietary composition, and decreasing levels of physical activity [18]. However, the central role of socioeconomic status (SES) is increasingly recognized. Socioeconomic disparities in mortality risk and prevalence of chronic conditions have worsened substantially over the past several decades in the U.S., a trend occurring in parallel with economic stagnation for lower-income households [19, 20]. Based on these trends, researchers hypothesize that lower SES is leading to worsening health in middle age, possibly through the negative impact of lower SES on factors such as environment, access to health care, and stress [21-23]. Research using data from the 2002-2016 National Health Interview Survey supports this hypothesis, showing how unfavorable trends in income and psychological distress are associated with worsening function over time, while improving educational attainment and decreasing rates of smoking are protective factors [12]. Given these trends towards worsening health and function among middle-aged people, there are concerns that without action, this age cohort will enter older age in worse health than the current cohort of older adults [21].

\section{Functional impairment in middle age is heterogeneous}

Many studies of middle-aged people with ADL impairment are cross-sectional and capture a heterogeneous group of individuals [7, 9, 10]. This group includes people with long-standing impairments that are congenital or developed in young adulthood, as well as people with impairments that developed for the first time in middle age. Research shows that both of these groups experience poorer health outcomes than people without such impairments. Individuals with longstanding disabilities are at disproportionate risk for poor health outcomes [24, 25], while people who develop new ADL impairment in middle age have a 1.5 - to 2.5 -fold increased risk of hospitalization, nursing home admission, and death $[13,14]$. These groups represent distinct populations, with different pathways to functional impairment and different needs, for whom different interventions may be appropriate. In this commentary, we will focus specifically on people who develop functional impairment for the first time in middle age.

\section{Functional impairment that develops in middle age has similarities to impairment that develops in older age, but also key differences}

Some risk factors for ADL impairment in middle and older age are similar, including having lower income, chronic medical conditions, depression, sensory impairment, low physical activity, reduced physical performance, and living in an unsafe neighborhood [26-30]. However, some established risk factors among older adults do not appear to be risk factors in middle-aged people, including female sex, cognitive impairment, and low body mass index (Table 1) [13, 14, 31-33]. Several factors may explain these differences. Older women are thought to be at increased risk for ADL impairment compared to men because they have a higher prevalence 
Table 1 Risk factors for ADL impairment by age group

\begin{tabular}{lc}
\hline Middle age and older age & Older age only \\
\hline Low income & Female sex \\
Chronic medical conditions (e.g., stroke, diabetes, arthritis, lung disease, obesity) & Cognitive impairment \\
Depression & Low body mass index \\
Sensory impairment & \\
Reduced physical performance & \\
Low physical activity & \\
Living in an unsafe neighborhood &
\end{tabular}

of disabling conditions, including osteoporosis and osteoarthritis [34-38]. These conditions do not become highly prevalent until age 65 , when gender differences in risk of ADL impairment emerge [37]. However, middleaged women have a higher prevalence of risk factors for ADL impairment than men. These risk factors include greater declines in strength [39-41] and lower scores on physical performance tasks including grip strength and chair rise [42, 43]. Greater loss of strength in women compared to men may result from the menopausal transition [41, 44]. Cognitive impairment strongly predicts ADL impairment among older adults but is relatively rare in middle age, making it challenging to examine its association with functional outcomes; the same is true for low body mass index [14].

Several studies also suggest that the traditional "hierarchy of disability" observed among older adults may differ in middle-aged people. When older adults develop difficulty performing ADL tasks, these difficulties develop in a predictable order, often called a hierarchy of disability [45]. Tasks requiring strength, balance, and coordination, such as bathing and dressing, are affected first, while tasks that require manual dexterity, such as eating, are affected later [45-49]. However, the order of onset of ADL impairments differs in middle-aged adults, with transferring and walking across a room being the most common initial impairments in this age group [14, 50, 51]. Additionally, in middle-aged adults, impairments in cognitively complex instrumental activities of daily living (IADLs) - such as managing medications and shopping - appear to be less common than ADL impairments $[46,52]$. In older adults, in contrast, IADL impairments typically precede ADL impairments $[13,14]$. The reasons for this difference by age group are not yet clear. Among older adults, cognitive impairment impacts the ability to perform cognitivelycomplex IADL tasks $[45,53]$. In middle-aged people, the lower incidence of IADL impairment may reflect the lower prevalence of cognitive impairment in this age group. Taken together, these differences suggest that the pathogenesis of ADL impairment differs by age, and point to the need to develop interventions that are tailored specifically to middle-aged people.
Functional impairment and disability in middle age impacts work force participation and public expenditures

Functional impairment and disability that develops before age 65 , often called pre-retirement age disability, has major impacts on work force participation and public expenditures. In 2018, 6.8 million disabled workers ages $45-64$ in the U.S. received disability benefits [54]. Individuals who develop disability experience substantial economic effects; one study showed that 10 years after onset of disability, people with chronic and severe disability had average declines of $79 \%$ in earnings and $35 \%$ in after-tax income; the average disabled worker experienced economic impacts about half that of individuals with severe and chronic disability [15]. Federal disability benefits for disabled workers include Social Security Disability Insurance and Supplemental Security Income programs and health insurance via Medicare and Medicaid. Public expenditures for these benefits exceed \$150 billion annually [55]. The number of disabled workers has recently fallen, a trend which may be related to the economic recovery and the shift towards jobs that require less physical labor [56]. However, worsening income inequality and health disparities may stall or reverse these positive trends [56].

Middle age may be an ideal time to intervene to prevent or delay the onset of functional impairment and mitigate associated burdens and costs

Several lines of research suggest that middle age is a promising time for intervention to delay or prevent functional impairment. First, middle-aged people who develop ADL impairment appear to have a higher capacity for improvement than do older adults. Studies show that ADL impairment in both middle age and older age is dynamic, with many people experiencing improvement in function after an initial episode of impairment [14, 57, 58]. However, the proportion of people who improve after an initial episode of impairment is higher among middle-aged than older adults. For example, in a prospective nationally representative study of men and women in the U.S. who were ages 50-56 at study enrollment, 22\% developed new ADL 
impairment before age 65 . Of individuals with new ADL impairment, $65 \%$ had stable or improved function at 10 year follow-up; risk of functional decline was similar in women versus men [14]. By contrast, in a separate prospective population-based study of men and women aged 85 or older in the Netherlands, only $14 \%$ of participants who developed new ADL impairment had stable or improved function at 5 years $[58,59]$. Men were less likely to decline over the follow-up period than were women (hazard ratio for decline, 0.75 [95\% CI, 0.58-0.96]). Other populationbased studies similarly show that the probability of recovery from disability decreases with increasing age $[60,61]$. These findings suggest that with appropriate interventions, middle-aged adults at high risk for impairment may be more likely to maintain independence than older adults. The greater resilience of middle-aged versus older adults may reflect in part changes in muscle that occur with aging and which may be accelerated in women during the menopausal transition, including loss of mass, strength, and function, termed sarcopenia [62]. Some theorize that because middle-aged adults have less sarcopenia than older adults, exercise interventions that prevent ADL impairment in older adults may be even more effective for middle-aged people [60,63].

Addressing ADL impairment earlier in the life course is also a promising strategy for proactively addressing the burdens and costs of ADL impairment, including impacts on work force participation and public expenditures. A growing body of research shows that functional impairment in both middle-aged and older adults have their roots in conditions that start in middle age, including arthritis, obesity, and depression [64-66]. Intervening in middle age thus has the potential not only to reduce the incidence of ADL impairment and associated adverse outcomes among middle-aged people, but also older people. This approach aligns with a growing consensus that achieving healthy aging requires a life-course approach to promoting health and function that starts decades before we enter traditional older age $[67,68]$. Taking a proactive approach to preventing functional impairment is even more pressing as the population of middle-aged people with functional impairment grows [12, 21, 22].

\section{Potential challenges to intervening in middle age}

To address functional impairment among the growing population of at-risk middle-aged people, we must consider several potential challenges.

Challenge 1: dynamism: functional impairments come and go One potential challenge is the dynamic nature of functional impairment in middle age. While functional impairment is also dynamic in older adults, it appears to be especially so in middle-aged adults, with a higher proportion of initial impairments improving among middle-aged compared to older people [14, 26, 59]. However, recent research among middle-aged people shows that an initial episode of functional impairment strongly predicts adverse outcomes including hospitalization, nursing home admission, and death, regardless of whether that impairment later regresses [13, 14]. This finding is consistent with research among older adults showing than an initial episode of functional impairment represents a "sentinel event" signaling the risk for future adverse outcomes [3, 61, 69-71]. Given that an initial episode of impairment has similar prognostic importance for middle-aged people, preventing an initial episode of functional impairment is also an important goal in this younger age group [13, 14].

\section{Challenge 2: follow-up time}

Another potential challenge is the long follow-up time that may be needed to observe the effectiveness of an intervention to prevent or delay functional impairment [60]. For interventions focused on preventing functional impairment in middle age, this is less of a concern as long as accurate prognostic models are available to identify those at highest risk for developing functional impairment in middle age. However, this is a challenge for life course interventions designed to intervene in middle age to prevent or delay functional impairment or other outcomes in older age. Such trials require long follow-up periods and associated challenges of participant retention and costs. Potential strategies for addressing these challenges include initially focusing on upstream outcomes that are strongly correlated with disability, including performance measures such as gait speed [72] and the Short Physical Performance Battery [73], or selfreported physical capacity [74]. However, it is important that these trials also incorporate methods for long-term follow-up of functional outcomes.

In the absence of randomized controlled trials, observational studies provide important evidence about the association of risk factors in middle age with late-life outcomes, while simulation studies model the impact of healthy life style changes in middle age (e.g., weight loss, quitting smoking) on late life health [75]. In the field of dementia prevention, the World Health Organization and others have used such evidence to develop evidence-based guidelines for life course approaches to reducing dementia incidence $[76,77]$. While some studies have examined the most efficacious late-life interventions to prevent disability [78], to our knowledge, we currently lack similar life course guidelines to prevent or delay functional impairment and disability. 
Challenge 3: potential similarities between interventions to prevent functional impairment and existing preventive care interventions

Another potential challenge is the perception that there is no added benefit to developing new interventions to prevent or delay functional impairment for middle-aged people, because existing primary care interventions already address risk factors for functional impairment. Currently, primary care for middle-aged adults focuses on addressing cardiovascular risk factors such as high blood pressure, performing screenings for cancer, diabetes, and other conditions, and targeting high-risk patients for prevention interventions such as statins. Preventive care for adults of all ages focuses on promoting healthy behaviors including physical activity, healthy diet, and smoking cessation. Many of these primary care interventions target risk factors that are also risk factors for functional impairment, including chronic health conditions and health-related behaviors.

However, several lines of research point to the importance of developing tailored interventions that specifically focus on preventing functional impairment in middle age. First, despite our health system's current focus on modifying cardiovascular risk factors and promoting healthy behaviors, the prevalence of functional impairment in middle age continues to increase. This suggests that our current clinical approaches are not enough to reverse trends towards worsening health in middle age. Second, functional impairment in both middle-aged and older people is multifactorial, meaning that these impairments result from the interaction of risk factors from multiple domains, including sociodemographics, health status, health-related behaviors, and the physical environment $[13,14,53]$. Thus, it is likely that interventions to address functional impairment will need to be multifactorial and coordinated, addressing multiple risk factors in concert. Third, individuals who develop functional impairment in middle age tend to be especially vulnerable, with a high prevalence of risk factors for poor health $[13,14,50]$. To improve outcomes for this high-risk group, a targeted approach may be most efficacious, rather than a diffuse approach that provides similar prevention advice to all patients. Last, function is the outcome that is most important to older adults [79]. Thus, interventions to prevent functional impairment may be especially motivating for patients because they align with their larger goals.

\section{Future directions and opportunities}

A robust body of research among older adults provides a framework to help inform and advance the science of functional impairment prevention among middle-aged people. Among older adults, research has focused on two key areas: first, identifying older adults who are at highest risk for functional impairment, and second, developing and testing interventions to prevent or delay impairment among those at highest risk [5]. This research shows that functional impairment among older adults is multifactorial, with risk factors encompassing demographics, socioeconomic status, health status, health-related behaviors (smoking, low physical activity), geriatric conditions (cognitive impairment, sensory impairment, urinary incontinence), social support, and environment (neighborhood safety, walkability) [53, 8082]. Researchers have used these findings to develop multifactorial prognostic models that are highly accurate in identifying those at highest risk [73, 83-85]. In turn, these risk factors and indices have informed a growing number of interventions to mitigate, prevent, or delay functional impairment among high-risk older adults [5, 6]. For example, a structured, moderate-intensity physical activity program targeted to high-risk adults ages 70 and older reduced incident mobility disability by $18 \%$ [4], and a multi-component home-based intervention including occupational therapy, nursing, and handyman visits decreased disability by $30 \%$ among high-risk older adults [86, 87].

This research among older adults has several implications for prevention of functional impairment among middle-aged people. Current health care for middle-aged people focuses mainly on prevention of chronic illnesses, such as heart disease and diabetes. Preventing chronic conditions that are risk factors for functional impairment is a key part of a proactive strategy to prevent functional impairment in middle age. However, risk factors for functional impairment in middle age span a broad range of domains, including not just chronic conditions but also sensory impairments and social and environmental risk factors. Thus, to address the increasing prevalence of functional impairment among middle-aged people, we need to adjust current paradigms to include prevention of functional impairment as an important clinical goal. To do so, we need to move prevention beyond a model that thinks only in terms of specific diseases and towards a broader, more holistic view of health that also considers function.

Accurate prognostic tools that can identify those at highest risk for functional impairment will help achieve this goal while minimizing burden for busy primary care providers. While prognostic tools exist to identify people ages 50 and older at risk for functional impairment [30], risk factors for functional impairment differ in middle versus older age [14]. For this reason, predictive models that focus specifically on middle-aged adults are likely to be able to identify and appropriately weight risk factors that are most important in this age group, leading to a more accurate index for middle-aged people. Additionally, clinical guidelines that build on existing 
epidemiologic research about risk factors for disability could help guide patients and providers in how to maintain and improve function in middle and older age, while we await more targeted interventions.

Interventions shown to be effective in preventing or reducing functional impairment among older adults provide a template for interventions for middle-aged people. The Lifestyle Interventions and Independence for Elders (LIFE) intervention was a multicenter randomized trial of a long-term structured physical activity program that was targeted to older adults (ages 70-89 years) at high risk for mobility disability [4]. The intervention incorporated twice-weekly center-based exercise sessions including aerobic, resistance, and flexibility training. Over 2.6 years' follow-up, individuals randomized to the intervention versus a health education program had an $18 \%$ lower risk of developing persistent mobility disability. Another recent trial is the Community Aging in Place Advancing Better Living for Elders (CAPABLE) study, a randomized trial of a 10-session, home-based, multidisciplinary program including visits by an occupational therapist, nurse, and handyman [86, 87]. This trial enrolled a vulnerable population of low income, community-dwelling older adults with baseline disability and focused on addressing not just deficits related to the person's capability, but also those related to environmental demand and adaptation. The multidisciplinary team conducted assessments with participants to identify their goals and unmet health and environmental needs and developed tailored plans to address those goals and needs. Over 5 months, participants in the intervention group had a $30 \%$ reduction in ADL disability scores compared to a control group receiving home visits from a research assistant.

Both of these approaches may inform interventions to prevent or mitigate functional impairment among middle-aged adults (Table 2). For middle-aged people whose main risk factor for functional impairment is declining strength and physical performance, an intervention focused on exercise, including aerobic, resistance, and flexibility training, may be effective. An exercisefocused approach may be particularly appropriate for women at risk for functional impairment, given greater declines in strength and physical performance among women compared to men [43-45]. However, for socioeconomically disadvantaged populations which experience health disparities and have a greater burden of health, social, and environmental risk factors, a multicomponent approach such as CAPABLE may be most appropriate. Indeed, CAPABLE is already being adapted for a high-risk population of formerly homeless adults [88], showing the potential to adapt this intervention for vulnerable middle-aged groups. Given evidence that worsening socioeconomic status is associated with the rising prevalence of functional impairment in middleaged people [21, 22], interventions such as CAPABLE have the potential to play an important role in mitigating these trends.

Adaptations of existing interventions will also need to account for differences between middle-aged and older adults. These include the differing epidemiology of functional impairment in middle-aged people and differences in life stage between middle-aged versus older adults. For example, a larger percentage of middle-aged people work compared to older adults. In $2018,80 \%$ of people ages $45-54$ and $65 \%$ of people ages $55-64$ participated in the U.S. civilian work force [89]. In contrast, $27 \%$ of people ages $65-74$ and just $8.7 \%$ of those aged 75 and older worked in 2018. A substantial percentage of middle-aged adults also care for children or parents [90]. Thus, the frequency or timing of interventions may need to be adjusted, and mobile health approaches and other flexible intervention delivery platforms may need to be considered.

\section{Conclusions}

The prevalence of functional impairment among middleaged Americans is increasing. Functional impairment in this age group is associated with adverse outcomes similar to those experienced by older adults, including hospitalization, nursing home admission, and death. Developing ADL impairment in middle age also impacts work force participation and health expenditures, not just in middle age but also older age. Middle-aged adults have a high capacity for recovery from functional impairment and many risk factors for functional impairment have their roots in middle age. Taken together, these findings suggest that middle age may be an ideal

Table 2 Promising intervention components to prevent, delay, or mitigate functional impairment in middle-aged adults

\begin{tabular}{lll}
\hline Intervention components & Exemplar intervention for older adults and impact & Target population \\
\hline $\begin{array}{l}\text { Structured exercise programs including } \\
\text { aerobic training, resistance training, and } \\
\text { flexibility training }\end{array}$ & $\begin{array}{l}\text { Lifestyle Interventions and Independence for } \\
\text { Elders (LIFE) Study Randomized Clinical Trial; } \\
\text { reduced risk of major mobility disability in at-risk } \\
\text { older adults }\end{array}$ & $\begin{array}{l}\text { May benefit middle-aged individuals whose main } \\
\text { risk factor for functional impairment is reduced } \\
\text { strength and physical performance, including post- } \\
\text { menopausal women }\end{array}$ \\
$\begin{array}{lll}\text { Multi-component interventions addressing } \\
\text { deficits related to physical capability and to } \\
\text { environmental demand and adaptation }\end{array}$ & $\begin{array}{l}\text { Community Aging in Place - Advancing Better } \\
\text { Lising for Elders (CAPABLE) study; reduced ADL }\end{array}$ & $\begin{array}{l}\text { May benefit middle-aged individuals with multiple } \\
\text { risk factors for functional impairment, including re- } \\
\text { duced physical performance and social and envir- } \\
\text { onmental risks }\end{array}$ \\
\hline
\end{tabular}


period to intervene to prevent or delay functional impairment. Multi-pronged efforts are needed to address the rising prevalence of functional impairment in middle age. These include developing improved prognostic tools to identify middle-aged people at highest risk for functional impairment and adapting existing interventions or developing novel interventions to prevent or delay functional impairment in this age group. Exercise interventions may be particularly effective for middle-aged people whose main risk factor for functional impairment is declining strength and physical performance; for more socioeconomically vulnerable populations, multicomponent interventions that address health, social, and environmental risk factors may be needed. In addition, we need to shift our health system towards recognizing functional impairment in middle age as a problem that is as prevalent and central to health and wellbeing as many chronic medical conditions.

\section{Abbreviations}

ADL: Activities of daily living; IADL: Instrumental activities of daily living; LIFE: Lifestyle Interventions and Independence for Elders;

CAPABLE: Community Aging in Place - Advancing Better Living for Elders

\section{Acknowledgements}

Not applicable.

\section{Authors' contributions}

RTB conceived of the manuscript, drafted and revised the manuscript, approved the final version of the manuscript, and is accountable for all aspects of work associated with this manuscript. KEC conceived of the manuscript, revised the manuscript, approved the final version of the manuscript, and is accountable for all aspects of work associated with this manuscript.

\section{Funding}

This work was supported by grants K23AG045290 and K76AG057016 from the National Institute on Aging, National Institutes of Health (Dr. Brown); a grant from the American Federation for Aging Research (Dr. Brown); grant P30AG044281 from the National Institute on Aging, National Institutes of Health (Drs. Brown and Covinsky); and grant K24AG029812 from the National Institute on Aging, National Institutes of Health (Dr. Covinsky). These funding sources had no role in the preparation, review, or approval of the manuscript. Drs. Brown and Covinsky are employees of the Department of Veterans Affairs. The opinions expressed in this manuscript may not represent those of the Department of Veterans Affairs.

\section{Availability of data and materials}

Not applicable.

\section{Ethics approval and consent to participate}

Not applicable.

\section{Competing interests}

The authors declare that they have no competing interests.

\section{Author details}

'Division of Geriatric Medicine, Perelman School of Medicine at the University of Pennsylvania, 3615 Chestnut Street, Philadelphia, PA 19104, USA. ${ }^{2}$ Geriatrics and Extended Care, Corporal Michael J. Crescenz Veterans Affairs Medical Center, Philadelphia, PA, USA. ${ }^{3}$ Center for Health Equity and Research Promotion, Corporal Michael J. Crescenz VA Medical Center, Philadelphia, PA, USA. ${ }^{4}$ Division of Geriatrics, University of California, San Francisco, CA, USA. ${ }^{5}$ San Francisco Veterans Affairs Medical Center, San Francisco, CA, USA.
Received: 30 August 2019 Accepted: 13 July 2020

Published online: 17 July 2020

\section{References}

1. Covinsky KE, Wu AW, Landefeld CS, Connors AF Jr, Phillips RS, Tsevat J, et al. Health status versus quality of life in older patients: does the distinction matter? Am J Med. 1999;106(4):435-40.

2. Fried TR, Bradley EH, Williams CS, Tinetti ME. Functional disability and health care expenditures for older persons. Arch Intern Med. 2001;161(21):2602-7.

3. Inouye SK, Peduzzi PN, Robison JT, Hughes JS, Horwitz RI, Concato J. Importance of functional measures in predicting mortality among older hospitalized patients. JAMA. 1998;279(15):1187-93.

4. Pahor M, Guralnik JM, Ambrosius WT, Blair S, Bonds DE, Church TS, et al. Effect of structured physical activity on prevention of major mobility disability in older adults: the LIFE study randomized clinical trial. JAMA. 2014;311(23):2387-96.

5. Daniels R, van Rossum E, de Witte L, Kempen Gl, van den Heuvel W. Interventions to prevent disability in frail community-dwelling elderly: a systematic review. BMC Health Serv Res. 2008;8:278.

6. Beswick AD, Rees K, Dieppe P, Ayis S, Gooberman-Hill R, Horwood J, et al. Complex interventions to improve physical function and maintain independent living in elderly people: a systematic review and meta-analysis. Lancet. 2008;371(9614):725-35.

7. Martin LG, Freedman VA, Schoeni RF, Andreski PM. Trends in disability and related chronic conditions among people ages fifty to sixty-four. Health Aff (Millwood). 2010:29(4):725-31.

8. Crimmins EM, Beltran-Sanchez H. Mortality and morbidity trends: is there compression of morbidity? J Gerontol B Psychol Sci Soc Sci. 2011; 66(1):75-86.

9. Freedman VA, Spillman BC, Andreski PM, Cornman JC, Crimmins EM, Kramarow $\mathrm{E}$, et al. Trends in late-life activity limitations in the United States: an update from five national surveys. Demography. 2013;50(2):661-71.

10. Martin LG, Schoeni RF. Trends in disability and related chronic conditions among the forty-and-over population: 1997-2010. Disabil Health J. 2014;7(1 Suppl):S4-14.

11. Zajacova A, Montez JK. Physical functioning trends among US women and men age 45-64 by education level. Biodemography Soc Biol. 2017; 63(1):21-30

12. Zajacova A, Montez JK. Explaining the increasing disability prevalence among mid-life US adults, 2002 to 2016. Soc Sci Med. 2018;211:1-8.

13. Brown RT, Diaz-Ramirez LG, Boscardin WJ, Lee SJ, Williams BA, Steinman MA Association of functional impairment in middle age with hospitalization, nursing home admission, and death. JAMA Intern Med. 2019;179(5):668-74.

14. Brown RT, Diaz-Ramirez LG, Boscardin WJ, Lee SJ, Steinman MA. Functional impairment and decline in middle age: a cohort study. Ann Intern Med. 2017:167(11):761-8

15. Meyer BD, Mok WK. Disability, earnings, income and consumption. J Public Econ. 2019:171:51-69.

16. Paez KA, Zhao L, Hwang W. Rising out-of-pocket spending for chronic conditions: a ten-year trend. Health Aff (Millwood). 2009:28(1):15-25.

17. Centers for Disease Control and Prevention (CDC). Prevalence and most common causes of disability among adults: United States, 2005. MMWR Morb Mortal Wkly Rep. 2009:58(16):421-6.

18. Hill JO, Wyatt HR, Peters JC. Energy balance and obesity. Circulation. 2012; 126(1):126-32.

19. Chetty R, Stepner M, Abraham S, Lin S, Scuderi B, Turner N, et al. The association between income and life expectancy in the United States, 2001 2014. JAMA. 2016;315(16):1750-66.

20. Wang $H$, Schumacher $A E$, Levitz $C E$, Mokdad AH, Murray CJ. Left behind: widening disparities for males and females in US county life expectancy, 1985-2010. Popul Health Metrics. 2013;11(1):8.

21. Case A, Deaton A. Rising morbidity and mortality in midlife among white non-Hispanic Americans in the 21st century. Proc Natl Acad Sci U S A. 2015 112(49):15078-83.

22. Case A, Deaton A. Mortality and morbidity in the 21st century. Brook Pap Econ Act. 2017:2017(1):397-476.

23. Muennig PA, Reynolds M, Fink DS, Zafari Z, Geronimus AT. America's declining well-being, health, and life expectancy: not just a white problem. Am J Public Health. 2018;108(12):1626-31.

24. lezzoni LI. Policy concerns raised by the growing U.S. population aging with disability. Disabil Health J. 2014;7(1 Suppl):S64-8. 
25. Krahn GL, Walker DK, Correa-De-Araujo R. Persons with disabilities as an unrecognized health disparity population. Am J Public Health. 2015; 105(Suppl 2):S198-206

26. Ostbye T, Taylor DH, Jung SH. A longitudinal study of the effects of tobacco smoking and other modifiable risk factors on ill health in middle-aged and old Americans: results from the health and retirement study and asset and health dynamics among the oldest old survey. Prev Med. 2002;34(3):334-45.

27. Deshpande N, Metter JE, Guralnik J, Bandinelli S, Ferrucci L. Sensorimotor and psychosocial determinants of 3-year incident mobility disability in middle-aged and older adults. Age Ageing. 2014;43(1):64-9.

28. Heiland EG, Welmer AK, Wang R, Santoni G, Angleman S, Fratiglioni L, et al. Association of mobility limitations with incident disability among older adults: a population-based study. Age Ageing. 2016;45(6):812-9.

29. Wray LA, Ofstedal MB, Langa KM, Blaum CS. The effect of diabetes on disability in middle-aged and older adults. J Gerontol A Biol Sci Med Sci. 2005;60(9):1206-11.

30. Deshpande N, Metter EJ, Guralnik J, Bandinelli S, Ferrucci L. Predicting 3-year incident mobility disability in middle-aged and older adults using physical performance tests. Arch Phys Med Rehabil. 2013;94(5):994-7.

31. Arterburn D, Westbrook EO, Ludman EJ, Operskalski B, Linde JA, Rohde P, et al. Relationship between obesity, depression, and disability in middleaged women. Obes Res Clin Pract. 2012;6(3):e197-206.

32. Karvonen-Gutierrez CA, Ylitalo KR. Prevalence and correlates of disability in a late middle-aged population of women. J Aging Health. 2013;25(4):701-17.

33. Zhao G, Ford ES, Li C, Crews JE, Mokdad AH. Disability and its correlates with chronic morbidities among U.S. adults aged $50-<65$ years. Prev Med. 2009:48(2):117-21.

34. Wray LA, Blaum CS. Explaining the role of sex on disability: a populationbased study. Gerontologist. 2001;41(4):499-510.

35. Oman D, Reed D, Ferrara A. Do elderly women have more physical disability than men do? Am J Epidemiol. 1999;150(8):834-42.

36. Leveille SG, Penninx BW, Melzer D, Izmirlian G, Guralnik JM. Sex differences in the prevalence of mobility disability in old age: the dynamics of incidence, recovery, and mortality. J Gerontol B Psychol Sci Soc Sci. 2000; 55(1):S41-50.

37. Murtagh KN, Hubert HB. Gender differences in physical disability among an elderly cohort. Am J Public Health. 2004;94(8):1406-11.

38. Whitson $H E$, Landerman LR, Newman AB, Fried LP, Pieper CF, Cohen HJ. Chronic medical conditions and the sex-based disparity in disability: the cardiovascular health study. J Gerontol A Biol Sci Med Sci. 2010;65(12):1325-31.

39. Danneskiold-Samsoe B, Bartels EM, Bulow PM, Lund H, Stockmarr A, Holm CC, et al. Isokinetic and isometric muscle strength in a healthy population with special reference to age and gender. Acta Physiol (Oxf). 2009;197(Suppl 673):1-68.

40. Samson MM, Meeuwsen IB, Crowe A, Dessens JA, Duursma SA, Verhaar HJ. Relationships between physical performance measures, age, height and body weight in healthy adults. Age Ageing. 2000;29(3):235-42.

41. Phillips SK, Rook KM, Siddle NC, Bruce SA, Woledge RC. Muscle weakness in women occurs at an earlier age than in men, but strength is preserved by hormone replacement therapy. Clin Sci (Lond). 1993;84(1):95-8.

42. Kuh D, Bassey EJ, Butterworth S, Hardy R, Wadsworth ME. Grip strength, postural control, and functional leg power in a representative cohort of British men and women: associations with physical activity, health status, and socioeconomic conditions. J Gerontol A Biol Sci Med Sci. 2005:60(2):224-31.

43. Bassey EJ, Mockett SP, Fentem PH. Lack of variation in muscle strength with menstrual status in healthy women aged 45-54 years: data from a national survey. Eur J Appl Physiol Occup Physiol. 1996;73(3-4):382-6.

44. Greeves JP, Cable NT, Reilly T, Kingsland C. Changes in muscle strength in women following the menopause: a longitudinal assessment of the efficacy of hormone replacement therapy. Clin Sci (Lond). 1999:97(1):79-84.

45. Ferrucci L, Guralnik JM, Cecchi F, Marchionni N, Salani B, Kasper J, et al. Constant hierarchic patterns of physical functioning across seven populations in five countries. Gerontologist. 1998;38(3):286-94.

46. Dunlop DD, Hughes SL, Manheim LM. Disability in activities of daily living: patterns of change and a hierarchy of disability. Am J Public Health. 1997; 87(3):378-83.

47. Yeh CJ, Wang CY, Tang PF, Lee MC, Lin HS, Chen HY. Hierarchy of higherlevel physical functions: a longitudinal investigation on a nationally representative population of community-dwelling middle-aged and elderly persons. Disabil Rehabil. 2012;34(15):1271-6.
48. Gerrard P. The hierarchy of the activities of daily living in the Katz index in residents of skilled nursing facilities. J Geriatr Phys Ther. 2013; 36(2):87-91.

49. Jagger C, Arthur AJ, Spiers NA, Clarke M. Patterns of onset of disability in activities of daily living with age. J Am Geriatr Soc. 2001;49(4):404-9.

50. Cimino T, Steinman MA, Mitchell SL, Miao Y, Bharel M, Barnhart CE, et al. The course of functional impairment in older homeless adults: disabled on the street. JAMA Intern Med. 2015;175(7):1237-9.

51. Wloch EG, Kuh D, Cooper R. Is the hierarchy of loss in functional ability evident in midlife? Findings from a British birth cohort. PLoS One. 2016; 11(5):e0155815.

52. Fried LP, Guralnik JM. Disability in older adults: evidence regarding significance, etiology, and risk. J Am Geriatr Soc. 1997;45(1):92-100.

53. Stuck AE, Walthert JM, Nikolaus T, Bula CJ, Hohmann C, Beck JC. Risk factors for functional status decline in community-living elderly people: a systematic literature review. Soc Sci Med. 1999;48(4):445-69.

54. Social Security Administration. Annual Statistical Report on the Social Security Disability Insurance Program 2018. https://www.ssa.gov/policy/ docs/statcomps/di_asr/index.html. Accessed 24 Feb 2020.

55. Autor D, Chandra A, Duggan M. Public health expenditures on the working age disabled: assessing Medicare and Medicaid utilization of SSDI and SSI recipients. Cambridge: MIT Working Paper, Massachusetts Institute of Technology; 2011.

56. Social Security Administration Office of Retirement and Disability Policy. Trends in Social Security Disability Insurance. https://www.ssa.gov/policy/ docs/briefing-papers/bp2019-01.html. Accessed 24 Feb 2020.

57. lezzoni LI, Kurtz SG, Rao SR. Trends in U.S. adult chronic disability rates over time. Disabil Health J. 2014;7(4):402-12.

58. Ylitalo KR, Karvonen-Gutierrez CA, Fitzgerald N, Zheng H, Sternfeld B, El Khoudary SR, et al. Relationship of race-ethnicity, body mass index, and economic strain with longitudinal self-report of physical functioning: the study of Women's health across the nation. Ann Epidemiol. 2013;23(7):401-8.

59. van Houwelingen AH, Cameron ID, Gussekloo J, Putter H, Kurrle S, de Craen AJ, et al. Disability transitions in the oldest old in the general population. The Leiden 85-plus study. Age (Dordr). 2014;36(1):483-93.

60. Karvonen-Gutierrez CA. The importance of disability as a health issue for mid-life women. Womens Midlife Health. 2015;1:10.

61. Hardy SE, Gill TM. Recovery from disability among community-dwelling older persons. JAMA. 2004;291(13):1596-602

62. Volpi E, Nazemi R, Fujita S. Muscle tissue changes with aging. Curr Opin Clin Nutr Metab Care. 2004;7(4):405-10.

63. Gill TM. Do the tenets of late-life disability apply to middle age? Ann Intern Med. 2017:167(11):818-9.

64. Covinsky KE, Yaffe K, Lindquist K, Cherkasova E, Yelin E, Blazer DG. Depressive symptoms in middle age and the development of later-life functional limitations: the long-term effect of depressive symptoms. J Am Geriatr Soc. 2010:58(3):551-6.

65. Freedman VA, Martin LG, Schoeni RF, Cornman JC. Declines in late-life disability: the role of early- and mid-life factors. Soc Sci Med. 2008;66(7): 1588-602.

66. Covinsky KE, Lindquist K, Dunlop DD, Gill TM, Yelin E. Effect of arthritis in middle age on older-age functioning. J Am Geriatr Soc. 2008;56(1):23-8.

67. Kuh D. A life course approach to healthy aging, frailty, and capability. J Gerontol A Biol Sci Med Sci. 2007;62(7):717-21.

68. Kuh D, Karunananthan S, Bergman H, Cooper R. A life-course approach to healthy ageing: maintaining physical capability. Proc Nutr Soc. 2014;73(2): 237-48.

69. Gaugler JE, Duval S, Anderson KA, Kane RL. Predicting nursing home admission in the U.S: a meta-analysis. BMC Geriatr. 2007;7:13.

70. Gill TM, Kurland BF. Prognostic effect of prior disability episodes among nondisabled community-living older persons. Am J Epidemiol. 2003;158(11): 1090-6

71. Hardy SE, Dubin JA, Holford TR, Gill TM. Transitions between states of disability and independence among older persons. Am J Epidemiol. 2005; 161(6):575-84

72. Studenski S, Perera S, Patel K, Rosano C, Faulkner K, Inzitari M, et al. Gait speed and survival in older adults. JAMA. 2011;305(1):50-8

73. Guralnik JM, Simonsick EM, Ferrucci L, Glynn RJ, Berkman LF, Blazer DG, et al. A short physical performance battery assessing lower extremity function: association with self-reported disability and prediction of mortality and nursing home admission. J Gerontol. 1994;49(2):M85-94. 
74. Leinonen R, Heikkinen E, Jylha M. Changes in health, functional performance and activity predict changes in self-rated health: a 10-year follow-up study in older people. Arch Gerontol Geriatr. 2002;35(1):79-92.

75. Danaei G, Pan A, Hu FB, Hernan MA. Hypothetical midlife interventions in women and risk of type 2 diabetes. Epidemiology. 2013;24(1):122-8.

76. Risk reduction of cognitive decline and dementia: WHO guidelines. Geneva: World Health Organization; 2019. https://www.who.int/mental_health/ neurology/dementia/english_foreward_executive_summary_dementia_ guidelines.pdf?ua=1. Accessed 24 Feb 2020.

77. Livingston G, Sommerlad A, Orgeta V, Costafreda SG, Huntley J, Ames D, et al. Dementia prevention, intervention, and care. Lancet. 2017;390(10113): 2673-734.

78. Freedman VA, Hodgson N, Lynn J, Spillman BC, Waidmann T, Wilkinson AM, et al. Promoting declines in the prevalence of late-life disability: comparisons of three potentially high-impact interventions. Milbank $\mathrm{Q}$. 2006;84(3):493-520.

79. Fried TR, McGraw S, Agostini JV, Tinetti ME. Views of older persons with multiple morbidities on competing outcomes and clinical decision-making. J Am Geriatr Soc. 2008;56(10):1839-44.

80. Sun VK, Stijacic Cenzer I, Kao H, Ahalt C, Williams BA. How safe is your neighborhood? Perceived neighborhood safety and functional decline in older adults. J Gen Intern Med. 2012;27(5):541-7.

81. Chen B, Covinsky KE, Stijacic Cenzer I, Adler N, Williams BA. Subjective social status and functional decline in older adults. J Gen Intern Med. 2012;27(6):693-9.

82. Tas U, Verhagen AP, Bierma-Zeinstra SM, Odding E, Koes BW. Prognostic factors of disability in older people: a systematic review. Br J Gen Pract. 2007;57(537):319-23.

83. Kim DH, Newman AB, Lipsitz LA. Prediction of severe, persistent activity-ofdaily-living disability in older adults. Am J Epidemiol. 2013;178(7):1085-93.

84. Tinetti ME, Inouye SK, Gill TM, Doucette JT. Shared risk factors for falls, incontinence, and functional dependence: unifying the approach to geriatric syndromes. JAMA. 1995;273(17):1348-53.

85. Fried LP, Tangen CM, Walston J, Newman AB, Hirsch C, Gottdiener J, et al. Frailty in older adults: evidence for a phenotype. J Gerontol A Biol Sci Med Sci. 2001;56(3):M146-56

86. Szanton SL, Thorpe RJ, Boyd C, Tanner EK, Leff B, Agree E, et al. Community aging in place, advancing better living for elders: a bio-behavioralenvironmental intervention to improve function and health-related quality of life in disabled older adults. J Am Geriatr Soc. 2011:59(12):2314-20.

87. Szanton SL, Xue QL, Leff B, Guralnik J, Wolff JL, Tanner EK, et al. Effect of a biobehavioral environmental approach on disability among low-income older adults: a randomized clinical trial. JAMA Intern Med. 2019;179(2):204-11.

88. Clinical and Community Research Pilot: Piloting the CAPABLE model in Permanent Supportive Housing. Southern California Clinical and Translational Science Institute. https://sc-ctsi.org/funding/awardees/ benjamin-henwood-1. Accessed 24 Feb 2020

89. U.S. Bureau of Labor Statistics. Civilian labor force participation rate by age, sex, race, and ethnicity. https://www.bls.gov/emp/tables/civilian-labor-forceparticipation-rate.htm. Accessed 24 Feb 2020.

90. National Alliance for Caregiving and the AARP Public Policy Institute. Caregiving in the U.S. https://www.aarp.org/content/dam/aarp/ppi/2015/ caregiving-in-the-united-states-2015-report-revised.pdf. Accessed 24 Feb 2020.

\section{Publisher's Note}

Springer Nature remains neutral with regard to jurisdictional claims in published maps and institutional affiliations.

Ready to submit your research? Choose BMC and benefit from:
- fast, convenient online submission
- thorough peer review by experienced researchers in your field
- rapid publication on acceptance
- support for research data, including large and complex data types
- gold Open Access which fosters wider collaboration and increased citations
- maximum visibility for your research: over 100M website views per year
At BMC, research is always in progress.
Learn more biomedcentral.com/submissions

